\title{
Etiological Evaluation of Headache Patients in a Tertiary Care Hospital
}

\author{
Dr. Md. Shah Alam ${ }^{1 *}$, Dr. Md. Ahsanul Kabir ${ }^{2}$, Dr. Abdullah Al Maruf ${ }^{3}$, Dr. Nayan Kanti Das ${ }^{4}$, Prof. M. A. Azhar ${ }^{5}$
}

${ }^{1}$ Junior Consultant, Medicine, Upazilla Health Complex, Kalihati, Tangail, Bangladesh

${ }^{2}$ Registrar, Endrocrionology, Mymensingh Medical College Hospital, Mymensingh, Bangladesh

${ }^{3}$ Assistant Registrar, Nephrology, Dhaka Medical College Hospital, Dhaka, Bangladesh

${ }^{4}$ Indoor Medical Officer, Medicine, Dhaka Medical College Hospital, Dhaka, Bangladesh

${ }^{5}$ Principal and Head of the Department of Medicine, Green Life Medical College Hospital, Dhaka, Bangladesh

DOI: $10.36347 /$ sjams.2020.v08i10.001

| Received: 23.09.2020 | Accepted: 01.10.2020 | Published: 03.10.2020

*Corresponding author: Dr. Md. Shah Alam

Abstract

Original Research Article

Background: Headache is a very common complain amongst patients attending inpatient and outpatient departments of Medicine and Neuromedicine. In this study an attempt has been made to evaluate the etiological and clinical pattern of headache in our populations. The results of the study will help prompt and early diagnosis of headache patients. Methods: This study was conducted in the department of Medicine and Neuromedicine of SSMC and Mitford Hospital from $1^{\text {st }}$ July, 2014 to $31^{\text {st }}$ December, 2014. This is a prospective observational study. Sample size is 100. Qualitative purposive sampling has been done. Sample has been selected according to inclusion and exclusion criteria. Proper history taking, thorough physical examination and necessary investigation have been done to find out the etiology of headache. The data has been recorded in a structured format and analyzed by computer software SPSS. Result: In the study mean age of the respondents was 39.8 \pm 26.66 (at 95\%CI). Male and female ratio was 0.72:1.This study revealed that out of 100 patients 60 patients had Tension type headache (TTH), 11 patients had migraine, 15 patients had Mixed cranial headache $(\mathrm{MCH}), 1$ patient to Cluster headache $(\mathrm{CH})$ and 13 patients had secondary headache. It was seen that most patients $(87 \%)$ suffered from primary headache with TTH being the commonest diagnosis. Females were more affected than male in all groups except secondary headache. There was decline in primary headache with advancing age as the number of secondary headaches increased. Investigations were needed in a very small group of patients. Conclusion: It is very important to differentiate the different types of headache. Knowledge about etiological pattern of headache will help clinically in prioritizing the patients, in planning investigations, early diagnosis and prompt management and prevent complications of the patients.

Keywords: Etiological Evaluation, hypertension, headache, migraine.

Copyright @ 2020: This is an open-access article distributed under the terms of the Creative Commons Attribution license which permits unrestricted use, distribution, and reproduction in any medium for non-commercial use (NonCommercial, or CC-BY-NC) provided the original author and source are credited.

\section{INTRODUCTION}

Headache is one of the most common presenting complaints of patients attending any health care delivery Centre. It is a rarity never to have suffered a headache [1]. Headaches may be classified as primary or secondary, depending on the underlying cause. Secondary headache may be due to structural, infective, inflammatory or vascular conditions, but these are dwelt with elsewhere [2]. So, it is important health problem.

As many as $90 \%$ individuals have at least one headache per year. Severe, disabling headache is reported to occur at least annually by $40 \%$ people worldwide [1].
As many as $90 \%$ individuals have at least one headache per year. Severe, disabling headache is reported to occur at least annually by $40 \%$ people worldwide [1]

Rasmussen et al showed that the lifetime prevalence of headache in general population was $93 \%$ for men and $99 \%$ for women [3]. The one year prevalence varies in different studies from 23.0 to $90.0 \%$ [3]. By contrast, in elderly population, prevalence of headache ranged from $5 \%$ to $50 \%$ in different studies indicating a decline with age $[4,3]$. In fact, the prevalence of primary headaches declines with age; whereas that of secondary headaches increases [5]. In spite of that, primary headaches are the most frequent headaches in elderly and secondary headaches account of no more than $10-20 \%$ of headaches diagnosed over 
65 years [6]. Headache occur in over $80 \%$ of women during their childbearing years [7[. Therefore, they often present during pregnancy. The hormonal changes accompanying the menstrual cycle, pregnancy and postpartum are thought to be responsible [8]. Tensiontype headache $(\mathrm{TTH})$ is more common than migraine. One study in Italy showed a prevalence of $2.6 \%$ for TTH in elderly compared with $1 \%$ for migraine. The study with Thai elderly found that the prevalence of TTH and migraine in elderly was $18.3 \%$ and $2.9 \%$ respectively [9].

Headache is the major cause for attendance in neurological outpatient clinics, representing approximately $15 \%$ of routine neurological attendance and reflecting the anxiety amongst both patients and doctors that headache may be due to a sinister cause [9]. Thus every patient with headache requires careful consideration and sometimes thorough investigation [4].

Secondary headache due to CNS diseases, metabolic abnormalities, hypertension, drug induced headache etc. are more frequent in elderly [4].

The first description of a migrainous personality was published by Harold Wolf in 1937 who reported an association between migraine and some psychiatric symptoms. Although this characterization of migrainous adults as obsessive, shy, obedient and with rigid and inflexible traits ${ }^{10}$ has since been abandoned, the concept at that time highlighted a need to investigate correlations between headaches and psychological factors $[10,11]$. Epidemiological studies have shown that psychiatric disorders occur more frequently in patients who suffer from recurring headaches [12].

The term chronic daily headache $(\mathrm{CDH})$ covers a group of primary headaches that occur more than fifteen days per month, with duration of a minimum of four hours, over at least three months [1315]. $\mathrm{CDH}$ include chronic migraine (CM), chronic tension-type headache (CTTH), hemicranias continua (HC), and new daily persistent headache (NDPH) [16]. CDHs affect from 3 to $5 \%$ of the general population, and account for approximately $40 \%$ of resources of clinics specialized in headaches [17]. Chronic migraine is the most prevalent subtype of $\mathrm{CDH}$ seen in tertiary care centers [18].

Many studies used the Minnesota Multiphasic Personality Inventory (MMPI) to investigate patients with different types of headaches or other pains. The highest scores were given to patients with the strongest or most frequent types of pain and to patients with long-lasting headaches. This perhaps justifies why "such psychological abnormalities, often seen in chronic headaches, are frequently interpreted as responses to chronic pain" [19].
In the case of migraine, Bigal and Lipton described it as a chronic disease with progressive and sporadic manifestations. In some people the very process of becoming chronic remains unclear [20, 21]. It is believed that progression of migraine leads to changes in the central nervous system that are manifested by changes in nociceptive and pain thresholds, such as central sensitization [22].

The fact that individuals with chronic headache, including migraine, regularly suffer from other comorbidities, indicates the need for studies on the possibility that the same pathophysiological mechanisms explain the two clinical manifestations [23]. The relationship between premorbid disorders may be causal or casual, or even share the same risk factors (genetic or environmental) producing a mental state which gives rise to the two conditions.

The CDH Group had the highest proportion of patients with dependent personality, anxiety with less concentration and productivity and depressive disorders. Moreover, two symptoms that are often present in depression were analyzed in particular; patients with $\mathrm{CDH}$ had more suicidal thoughts and despair among those with $\mathrm{CDH}$. Among patients without depression, although there was no significant difference between the two groups regarding suicidal thoughts, patients with $\mathrm{CDH}$ presented more hopelessness.

In the $\mathrm{CDH}$ group, no difference was found comparing genders in relation to patients presenting neuroticism symptoms in general. However, on analyzing subtypes of disorders separately, it was noted that, in this group, women had more depression and suicidal ideation than men.

$\mathrm{CDH}$ patients, on the other hand, have the opposite stance, an anxious search with dependent, a disorganized state and irritable mood with less control, a depressive anxious apathy, loss of hope and suicidal ideation.

So, it is possible to understand the despair, suicidal ideation and the larger number of combined disorders as a collapse of the organism in successive attempts to adapt to continuous pain, typical of a stress exhaustion stage [21].

Patients with $\mathrm{CDH}$ tend to have dependent personality disorder, low production and concentration, anxiety, depression, suicidal ideation and hopelessness, superimposing two or more psychological disorders. These factors should be considered for a better resolution in the treatment of $\mathrm{CDH}$.

It is primarily a neurological symptom but most often it is not associated with any other neurological features [24]. I will consider most common 
and neurological causes of headache. There is not much study regarding headache in our country so far. So this type of study will help the headache patients in future. Though headache is commonly encountered in outpatient and inpatient department of our hospitals, it is sometimes not possible by the physician to find out exact etiology by taking history and rational investigations. It is due to overburden of the patients and also for the financial constraints of the patient. If we find out the exact etiological pattern of headache to evaluate the patient, then we can serve the patient better in this regard.

\section{ОВJECTIVE}

\section{General Objective}

To find out the etiology, clinical presentation of headache patients attending a tertiary care hospital.

\section{Specific Objective}

- To find out demographic pattern of the patients presented with headache.

- To find out etiology of headache.

- To study the pattern of clinical presentation of patients with headache.

\section{Methodology}

\section{Study Type}

This is a prospective observational study.

\section{Study Place and Period}

-This study was done at Medicine and Neuromedicine inpatient outpatient departments of Sir Salimullah Medical College and Mitford Hospital, Dhaka $1^{\text {st }}$ July, 2014 to $31^{\text {st }}$ December, 2014

\section{Sampling Method}

- The sample was collected by convenient sampling

\section{Study Population}

- Patients attending with headache in Medicine and Neuromedicine inpatient outpatient departments of Sir Salimullah Medical College and Mitford Hospital, Dhaka

\section{Inclusion Criteria}

- Patients presenting with headache in indoor and outdoor of Medicine and Neuro-medicine department of Sir Salimullah Medical College and Mitford hospital, during the study period.

- Patients over the age of 18 years.

- Giving informed written consent.

\section{Exclusion Criteria}

- Age at or below 18 years.

- Patient not given consent.

\section{Procedure of Data Collection}

Detailed history was taken, then thorough clinical examinations, necessary investigations (if needed) for headache wasdone. All these data was collected by using preformed data sheet. According to the final diagnosis of the patient the headache was identified as primary or secondary. Primary headache was further classified as TTH, migraine, mixed cranial headache $(\mathrm{MCH})$, cluster headache and others. Other than $\mathrm{MCH}$ other types were diagnosed as standard protocol. Headache that had mixed features of TTH and migraine were grouped as MCH. Secondary headache were further classified according to the underlying cause.

\section{Statistical Analysis}

The statistical analysis was carried out using the Statistical Package for Social Sciences version 20.0 for Windows (SPSS Inc., Chicago, Illinois, USA). Qualitative variables of this study have been expressed as percentage. Quantitative variables are expressed as mean \pm standard deviation. Test of significance was performed by unpaired t-test for quantitative variables. A "p" value $<0.05$ was considered as significant.

\section{Results \\ Age of the Respondents}

Table-1: Statistical distribution of age of the respondents by sex $($ N100)
\begin{tabular}{|l|l|l|l|}
\hline Sex of the respondents & Mean age & Std. deviation & Median age \\
\hline Male & 40.3 & 13.033 & 49.5 \\
\hline Female & 39.3 & 10.083 & 49.5 \\
\hline Total & 39.8 & 11.558 & 49.5 \\
\hline
\end{tabular}

Mean age of the male respondents was $40.3 \pm 26.033$ (at 95\% CI) and mean age of the female respondents was 39.3 $\pm 26.66($ at $95 \% \mathrm{CI}$ ). Median age was reported 49.5 years. Total mean age of the respondents was $39.8 \pm 26.66$ (at $95 \% \mathrm{CI}$ ). As mean age appears to be less than median age for each sex, it indicates that the study population representing headache patients had a predilection towards younger age group, hence having a left skewed distribution. 


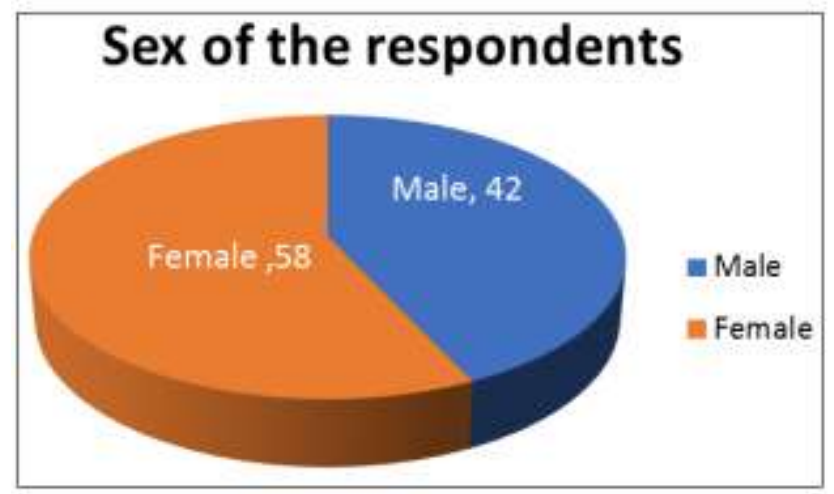

Fig-1: Pie diagram of the sex distribution of respondents by sex (N 100)

Out of 100 respondents $58(58 \%)$ were female and $42(42 \%)$ were male. Male and female ratio was $0.72: 1$.

Table-2: Frequency distribution of respondents by $\operatorname{sex}(\mathbf{N 1 0 0})$

\begin{tabular}{|l|l|l|}
\hline Sex & Frequency & Percent \\
\hline Male & 42 & 42 \\
\hline Female & 58 & 58 \\
\hline Total & 100 & 100 \\
\hline
\end{tabular}

Out of 100 respondents $58(58 \%)$ were female and $42(42 \%)$ were male. Male and female ratio was $0.72: 1$.

\section{Periodicity of Headache}

Table-3: Frequency distribution of the respondents by periodicity of pain. (N100)

\begin{tabular}{|l|l|l|}
\hline Periodicity of pain & Frequency & Percent \\
\hline One attack in a month & 22 & 22 \\
\hline $\begin{array}{l}\text { More than one attacks in a } \\
\text { month }\end{array}$ & 49 & 49 \\
\hline Daily attack & 29 & 29 \\
\hline total & 100 & 100 \\
\hline
\end{tabular}

$22(22 \%)$ respondents had suffered from less than one attack of headache in a month, 49 (49\%)had one or more attack in a month and 29(29\%) had daily attack.
Table-4: Frequency distribution of respondents by severity of pain (ref. Appendix B) (N100)

\begin{tabular}{|l|l|l|}
\hline Severity of pain & Frequency & Percent \\
\hline Mild & 45 & 45 \\
\hline Moderate & 35 & 35 \\
\hline Severe & 20 & 20 \\
\hline total & 100 & 100 \\
\hline
\end{tabular}

According to severity of attack (measured by a severity scale described in appendix B) 45(45\%) respondents had mild headache, $35(35 \%)$ had moderate and $20(20 \%)$ had severe headache.

Table-5: Frequency distribution of relieving factors

\begin{tabular}{|l|l|l|}
\hline Reliving factors & Frequency & Percent \\
\hline Drugs & 86 & 54.4 \\
\hline Sleep & 42 & 26.6 \\
\hline Massage & 13 & 8.2 \\
\hline Rest & 12 & 7.6 \\
\hline Posture & 5 & 3.1 \\
\hline
\end{tabular}

$86(54.4 \%)$ reported drugs to relieve their headache. Sleep, massage and rest acted as relievers of headache in 42 (26.6\%), 13 (8.2\%), 12 (7.6\%) respondents respectively.

\section{Neurological Deficit and Fundoscopic Findings}

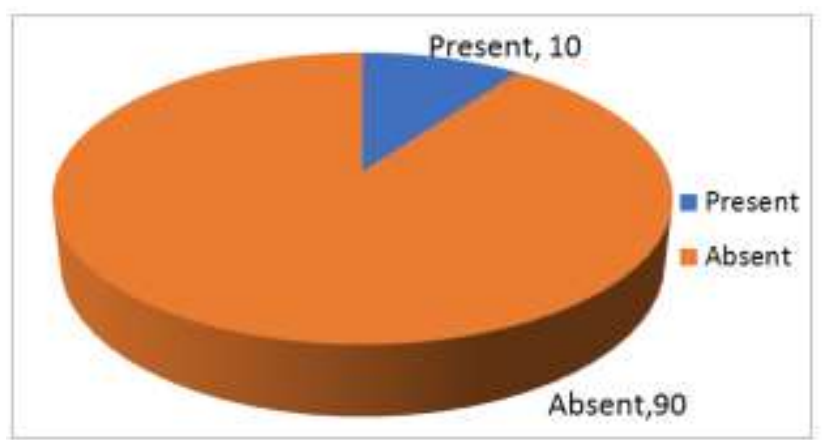

Fig-2: Frequency distribution of respondents by neurological deficit or focal sign (N 100) 
Among 100 patients only 10 respondents had any neurological deficit or focal sign. Fundoscopic examination revealed that 90 respondents had normal findings and 3 respondents had papilledema.

Table-6: Periodicity of primary type headache (N87)

\begin{tabular}{|l|l|l|l|l|}
\hline \multirow{2}{*}{ Primary headache } & \multicolumn{2}{|l|}{ Periodicity of pain } & \multirow{2}{*}{ Total } \\
\cline { 2 - 4 } & <one attack in a month & One or more attacks in a month & Daily attack & \\
\hline TTH & $9(15 \%)$ & $25(41.7 \%)$ & $26(43.3 \%)$ & $60(100 \%)$ \\
\hline Migraine & $4(36.4 \%)$ & $7(63.6 \%)$ & $0(.0 \%)$ & $11(100 \%)$ \\
\hline MCH & $3(17.6 \%)$ & $5(33.3 \%)$ & $7(46.7 \%)$ & $15(100 \%)$ \\
\hline Cluster headache & $1(100 \%)$ & $0(.0 \%)$ & $0(.0 \%)$ & $1(100 \%)$ \\
\hline Total & $17(19.5 \%)$ & $37(42.5 \%)$ & $33(37.9 \%)$ & $87(100 \%)$ \\
\hline
\end{tabular}

26(43.3\%) TTH patients had complaints of daily headache while $25(36.4 \%)$ had one or more attack in a month. None had been suffered from daily attack of migraine. 7(63.6\%) respondents of migraine group and $5(33.3 \%)$ respondents of $\mathrm{MCH}$ group had one or more attacks on every month.

Table-7: Character of headache in primary headache ( $N$ 87)

\begin{tabular}{|l|l|l|l|l|l|}
\hline \multirow{2}{*}{ Character of pain } & \multicolumn{2}{l|}{ Types of primary headache } & \multirow{2}{*}{ Total } \\
\cline { 2 - 5 } & TTH & Migraine & MCH & Cluster headache & \\
\hline Pulsatile & $3(5 \%)$ & $9(81.8 \%)$ & $2(13.3 \%)$ & $0(.0 \%)$ & $14(16.0 \%)$ \\
\hline Pinprick & $1(1.6 \%)$ & $1(9.1 \%)$ & $1(6.7 \%)$ & $0(.0 \%)$ & $3(3.4 \%)$ \\
\hline Tingling & $3(5 \%)$ & $1(9.1 \%)$ & $6(40.2 \%)$ & $1(100 \%)$ & $11(\%)$ \\
\hline Dull & $30(48 \%)$ & $0(.0 \%)$ & $2(13.3 \%)$ & $0(.0 \%)$ & $32(\%)$ \\
\hline Penetrating & $4(6.4 \%)$ & $0(.0 \%)$ & $2(13.3 \%)$ & $0(.0 \%)$ & $6(\%)$ \\
\hline compressive & $19(30.4 \%)$ & $0(.0 \%)$ & $2(13.3 \%)$ & $0(.0 \%)$ & $21(\%)$ \\
\hline Total & $60(100 \%)$ & $11(100 \%)$ & $15(100 \%)$ & $1(100 \%)$ & $87(100 \%)$ \\
\hline
\end{tabular}

In terms of character of the pain $30(48.0 \%)$ patients of TTH experienced dull pain, while 19(30.4\%) had compressive. By contrast majority of migraine suffers, $9(81.8 \%)$ had suffer pulsatile pain. Character of pain was more or less evenly distributed in $\mathrm{MCH}$ group with tingling type being most common (40.2\%).

Table-8: Relieving factors of primary headache (N 87)

\begin{tabular}{|l|l|l|l|l|}
\hline \multirow{2}{*}{ Primary headache } & \multicolumn{4}{|l|}{ Relieving factors } \\
\cline { 2 - 5 } & Drugs & Sleep & Rest & Massage \\
\hline TTH & $49(81.6 \%)$ & $11(18.3 \%)$ & $4(6.6 \%)$ & $6(10.0 \%)$ \\
\hline Migraine & $11(100.0 \%)$ & $3(27.27 \%)$ & $1(9.1 \%)$ & $0(.0 \%)$ \\
\hline MCH & $13(86.8 \%)$ & $4(26.6 \%)$ & $2(13.3 \%)$ & $0(.0 \%)$ \\
\hline
\end{tabular}

Drugs relieved pain in all migraine sufferers $(100 \%)$. It was also commonest reliving factor in TTH and $\mathrm{MCH}$ with $49(81.6 \%)$ and $13(86.6 \%)$ patients opting for it respectively.

Table-9: Co-existing symptoms in primary headache (N87)

\begin{tabular}{|l|l|l|l|l|l|}
\hline \multirow{2}{*}{ Primary headache } & \multicolumn{5}{l|}{ Co-existing symptoms } \\
\cline { 2 - 6 } & Nausea & Vomiting & Anxiety & Photophobia & Visual disturbance \\
\hline TTH & $12(20.0 \%)$ & $1(1.6 \%)$ & $47(78.3 \%)$ & $3(5.0 \%)$ & $4(6.6 \%)$ \\
\hline Migraine & $10(90.9 \%)$ & $6(45.5 \%)$ & $1(9.0 \%)$ & $7(63.6 \%)$ & $7(63.6 \%)$ \\
\hline MCH & $10(66.6 \%)$ & $2(13.3 \%)$ & $9(60.0 \%)$ & $8(53.3 \%)$ & $3(20.0 \%)$ \\
\hline
\end{tabular}

Nausea and vomiting were closely associated with migraine as $10(90.9 \%)$ and $5(45.5 \%)$ patients with migraine had them respectively. Photophobia and visual disturbance were also predominantly associated with migraine. 47(78.3\%) TTH patients had anxiety which was less common in migraine with only $1(9.0 \%)$ patients.

\section{DISCUSSION}

This study was undertaken to evaluate the etiological pattern of headache inpatient and outpatient departments of Medicine and Neuro medicine of SSMC and Mitford hospital to identify the exact cause of it. Selection of the patients for the study was randomly made irrespective of their sex and education. Headache was mostly diagnosed as clinically and some selective investigations were done for some selective patients. 
Mean age of the study group respondents was 39.8 years with a standard deviation of \pm 11.5 years. Median age was reported 49.5 years. Maximum 44 respondents $(44 \%)$ were within 30-39 years age group. Next highest respondent's age group was 40-49 years with $35(35 \%)$ respondents. Out of 100 respondents $58(58 \%)$ were female and $42(42 \%)$ were male. Male and female ratio was $0.72: 1$. In a study on Thai elderly, male to female ratio was $0.8: 1$ [3]. A figure similar to the findings of the study was found by Habib $M$ and Solomon Gd.where male to female ratio was $0.5: 1$ in both cases [25, 26].

Maximum 40 (40\%), respondents had dull type of headache. Second highest group with24 (24\%) respondents had compressive type of headache. $14(14 \%)$ had pulsatile type of headache, and $11(11 \%)$ had tingling type of headache. According to severity of attack (measured by a severity scale described in appendix B) $45(45 \%)$ respondents had mild headache, $35(35 \%)$ had moderate and $20(20 \%)$ had severe headache.

This findings is similar to the observations of prencipe $M$ [27]. In their study they found $60 \%$ patients were suffering from mild to moderate headache and proportion of patients with moderate to severe attacks were higher in patients with migraine than in those with $\mathrm{TTH}(82.6 \%$ and $35.8 \%$ respectively).

Stress was found to be the commonest precipitating factor. Out of all respondents 65 (38.7\%) had reported stress as a precipitating factor for the headache. Physical activity, fatigue and sleeping disturbance was reported as precipitating factors by $26(15.5 \%), 20(11.9 \%)$ and $20(11.9 \%)$ respondents respectively. $86(54.4 \%)$ reported drugs to relieve their headache.

Out of all respondents $87(87 \%)$ had primary type of headache and 13(13\%) had secondary type of headache. TTH was found commonest variants.62 (62\%) respondents had TTH, 14(14\%) had MCH and $11(11 \%)$ had migraine.

Out of 100 respondents $81(81 \%)$ respondents did not required any radiological investigations. CT scan and MRI scan were done in cases with history of head trauma and other CNS disorders.14(14\%) cases underwent CT scan of head and 4(4\%) underwent MRI scan of brain. These investigations revealed stroke in $3(3 \%)$ cases and intracranial neoplasm in $1(1 \%)$ case. $10(10 \%)$ cases did not have any neuroimaging finding.

One study by Habib $M$ found that neuroimaging was done in 135 patients out of which $38.39 \%$ had abnormal findings. This is consistent with the findings in this study [25].
The number $(13 \%)$ patients with secondary headache was too small to bring out any consistent patterns in their presentation though patients with IIH had nausea and vomiting more than others. Only one patient with secondary headache was diagnosed to have brain tumor. This may be due to the fact almost all patients with tumor are referred to the department of neurosurgery.

\section{Conclusion}

This study revealed that though there is some variation of age and sex incidence compared with western studies, the etiological pattern, symptomatology and physical signs, correlates with other studies of home and abroad.

There can be no doubt that whatever the mode of presentation, with the help of clinical skills and minimum laboratory investigations, correct diagnosis and proper management can be provided and complication may be prevented. This cost effective management will help our poor community and nation as a whole.

\section{REFERENCE}

1. Raskin NH. Headache. In: Kasper DL, Braunwald E, Fauci AS, Mauser SL, Longo DL, Jameson JL, editors. Harrison's principles of internal medicine.16th ed. New York: Mc Graw-Hill Company; 2005; 1:85-94.

2. Walker Brain R, Colledge Nicki R, Ralston Stuart H, Penman Ian D: Davidson's Principles and Practice of Medicine, 22th edition: 2014; 26:1176.

3. Srikiatkhachorn A. Epidemiology of headache in the thai elderly: a study in the Bangka home for the aged. Headache. 1997:31:677-81.

4. Hale WE, May Fe, Marks RG, Moore MT, Stewart RB. Headache in the elderly: an evaluation of risk factors. Headache. 7987; 27:272-6.

5. Pascual J, Berciano J. Experience in the diagnosis of headaches that start in elderly people. J Neurol Neurosurg Psychiatry.1994; 57:1255-7.

6. Edmieads J. Headache in the elderly. In: Olesen J, Tfelt-Hansen P, Welch KMA, editors. The headaches, $2^{\text {nd }}$ ed. Philadelphia: Lippincott Williams \& Wilkins, 2000; 947-51.

7. Waters WE, O'connor PJ. Epidemiology of headache and migraine in women. $J$ Neurol Phychiatgry. 1971; 34: 148.

8. Scharff L. Marcus DA, Turk DC. Headache during pregnancy and in the postpartum: a prospective study. Headache. 1997; 37: 208.

9. Poro'utka SJ. Drugs effective in therapy of migraine. Hardman JG editor. In: Goodman and Gillman's the pharmacological basis of therapeutics, 9th ed. New York: McGraw-Hill Books Inc. 1996; 487-502. 
10. Wolff HG. Personality features and reactions of subjects with migraine. Arch Neurol Psychiatry. 1937; 37:895.

11. Andrasik F, Blanchard EB, Arena JG, Teders SJ, Teevan RC, Rodichok LD. Psychological functioning in headache sufferers. Psycho Med. 1982;44:171-182.

12. Merikangas KR, Steavens DE. Comorbidity of migraine and psychiatric disorders. Neurol Clin. 1997; 15:115-123.

13. Departamento de Ciências Neurológicas, Faculdade de Medicina de São José do Rio Preto, Sao Jose do Rio Preto SP, Brazil.

14. Departamento de Neurologia, Faculdade de Medicina de São José do Rio Preto, Sao Jose do Rio Preto SP, Brazil.

15. NeurologiaClínica, Faculdade de Medicina de São José do Rio Preto, Sao Jose do Rio Preto SP, Brazil.

16. Halker RB, Hastriter EV, Dodik DW. Chronic daily headache: an evidence-based and systematic approach to a challenging problem. Neurology. 2011;76(Suppl 2):S537-S543.

17. Scher AI, Stewart WF, Liberman J, Lipton RB. Prevalence of frequent headache in a population sample. Headache. 1998;38:497-506.

18. Bigal ME, Rapoport AM, Lipton RB, Tepper SJ, Sheftell FD. Assessment of migraine disability using the migraine disability assessment (MIDAS) questionnaire: a comparison of chronic migraine with episodic migraine. Headache. 2003;43:336342 .
19. Huber D, Henridh G. Personality traits and stress sensitivity in migraine patients. Behav Med. 2003; 29:4-13.

20. Haut SR, Bigal ME, Lipton RB. Chronic disorders with episodic manifestations: Focus on epilepsy and migraine. Lancet Neurol. 2006;5:148-157.

21. Bigal ME, Lipton RB. Concepts and mechanisms of migrainechronification. Headache. 2008;48:715.

22. Welch KM, Nagesh V, Aurora S, Gelman N. Periaqueductal gray matter dysfunction in migraine: cause or the burden of illness? Headache. 2001;41:629-637.

23. Zukerman E. Fisopatologia da cefaléiacrônicadiária. Einstein. 2004; 2(Suppl 1):S5-S7.

24. Allen CM, Lueck CJ, Dennis M. Neurological disease. In: Boon NA, Coiledge Nr, Walker BR, Hunter JA, editors. Davidson's principle and practice of medicine. 20th ed. Ebinburagh: Churchill livingstone; 2006:1145-256.

25. Habib M, Alam B, Hoque A, Hoque B, Mohammad QD. Headache study of 3350 cases. Bangladesh J Neurosci. 2001;17(1):1-5.

26. Solomon GD, Kunkel RS, Frame J. Demographics of headache in elderly. Headache. 1990; 30:273-6.

27. Prencipe M, Casini AR, Ferretti C, Santini M, Pezzella F, Scaldaferri N, Culasso F. Prevalence of headache in an elderly population: attack frequency, disability, and use of medication. Journal of Neurology, Neurosurgery \& Psychiatry. 2001 Mar 1;70(3):377-81. 